\title{
ACONSELHAMENTO LINGUAGEIRO NO PROCESSO DE APRENDIZAGEM DE INGLÊS
}

\section{LANGUAGE ADVISING IN THE PROCESS OF LEARNING ENGLISH}

\author{
Walkyria Magno e Silva* \\ Larissa Dantas \\ Maria Clara Vianna Sá e Matos \\ Marja Ferreira Martins
}

\section{RESUMO}

Nos últimos anos tem se configurado um outro personagem no contexto do ensino e aprendizagem de línguas estrangeiras: o conselheiro linguageiro (CL). Neste texto propomos uma definição do que seja o aconselhamento linguageiro (AL) e expomos alguns dos papeis do CL, comparando-os com os do professor; levantamos ideias a respeito do lócus do CL nas instituições e das melhores práticas desse agente de aprendizagem. Esse experimento desenvolveu-se em uma universidade no norte do Brasil e envolveu alunos e professores de línguas estrangeiras. Os dados que aparecem neste texto são de alunos e conselheiros de inglês. Em seguida mostramos o impacto dessa ação na autonomização e na motivação dos aprendentes e como esse diálogo entre CL e aprendente pode se dar por meio de recursos tecnológicos mais disponíveis do que o contato face a face.

Palavras-chave: aconselhamento linguageiro; aprendizagem de inglês como língua estrangeira; autonomia.

\section{ABSTRACT}

Another agent has appeared in the foreign languages teaching and learning context in the recent years: the language learning adviser (LLA). A working definition of this construct is presented in this text. The roles of this agent are shown and compared to the roles played by the teacher. The place where language advising happens in the institutions is presented and the best practices are described. This experiment was developed in a university in Northern Brazil and it involved teachers and students of foreign languages. The data comes from English language advisers and students. Some of the evidences of the impact of this professional on students' autonomization and motivation is described. Finally, a counseling

\footnotetext{
* UFPA, Belém (PA), Brasil.wmagno@ufpa.br; UFPA, Belém (PA), Brasil. dantaslarissa@yahoo.com. br; UFPA, Belém (PA), Brasil. matos_mariaclara@yahoo.com.br; UFPA, Belém (PA), Brasil. marja_ufpa@hotmail.com.
} 
experience conducted through technological resources, when face to face contact was not possible, is shown.

Keywords: language advising; English as a foreign language learning; autonomy.

\section{INTRODUÇÃO}

Neste texto trazemos à discussão da comunidade de profissionais dedicados ao ensino de línguas estrangeiras uma outra figura: a de um conselheiro linguageiro (CL). De março de 2011 a fevereiro de 2013, desenvolveu-se em uma universidade no norte do Brasil o projeto de pesquisa intitulado Aconselbamento Linguageiro Visando à Autonomia e à Motivação na Aprendizagem de Linguas Estrangeiras. Este projeto agregou professores pesquisadores, mestrandos, bolsistas do programa PIBIC e licenciandos voluntários já proficientes em torno do estudo de como um conselheiro linguageiro pode alavancar o processo de aprendizagem de alunos de Letras com habilitação em uma língua estrangeira, que estejam enfrentando dificuldades na sua trajetória de aprendizagem. Essas dificuldades podem ser advindas da falta de vivência na LE anteriormente a seu ingresso na universidade ou da inabilidade em lidar com os novos desafios enfrentados no ensino superior. Fatores tais como motivação e autonomia são fortemente mobilizados nesse trabalho.

Cada conselheiro linguageiro orienta dois ou três aconselhados. Isso porque as relações construídas entre eles demandam tempo e atenção individualizada. Cada conselheiro encontra-se com seus aconselhados uma vez por semana ou por quinzena, disponibilizando ainda seu contato eletrônico ou até mesmo telefônico para algum apoio emergencial. Os encontros entre conselheiro e aconselhado podem ocorrer individualmente com cada aconselhado ou em duplas de aconselhados com um só conselheiro. Além disso, os conselheiros linguageiros reúnem-se semanalmente para discutir o andamento das sessões com seus aconselhados e para estudar textos teóricos de apoio ao seu trabalho.

Os dados apresentados neste texto provém de pares de conselheiros e aconselhados de inglês. Participaram como conselheiros professores e alunos de inglês e como aconselhados diversos aprendentes aqui referidos por A1, A2 e A3. Os dois primeiros são alunas em começo de curso que não haviam tido contato com inglês antes do ingresso na universidade. Os excertos de suas falas são de sessões gravadas no decorrer do processo de aconselhamento e posteriormente transcritos. A3 é do sexo masculino e estava em fase de conclusão de curso, já redigindo sua monografia. Os excertos de A3 que constam neste texto foram diretamente 
copiados dos registros dos contatos eletrônicos mantidos com a conselheira. Os dados foram coletados entre maio de 2011 e abril de 2012 e constam dos relatórios parciais do projeto de pesquisa.

Expomos em primeiro lugar o que vem a ser a figura do conselheiro linguageiro. Em seguida, mostramos como o trabalho de aconselhamento linguageiro pode levar à maior autonomização do aprendente. Depois, explicamos como lidamos com o processo motivacional dentro das sessões de aconselhamento, mostrando o importante papel da motivação na aprendizagem de LE. Finalmente, relatamos um caso de aconselhamento que, dada a impossibilidade de encontros presenciais entre conselheiro e aconselhado, foi realizado por meios virtuais.

\section{ACONSELHAMENTO LINGUAGEIRO: O QUE É, COMO SE FAZ?}

Nesta seção propomos uma definição operacional de conselheiro linguageiro (CL) e explicitamos as bases teóricas para o surgimento dessa figura no cenário do ensino e aprendizagem de línguas estrangeiras. Tentamos estabelecer uma diferenciação do papel do conselheiro linguageiro em contraste com o papel do professor.

Dentro de um centro tido como modelo na Europa, Mozzon-McPherson (2007) descreve a figura do conselheiro linguageiro como gerador de sinergia no processo de aprendizagem dos alunos. Nesse contexto, os conselheiros dominam não só a língua estrangeira em foco como também os instrumentos e técnicas necessários para criar um ambiente favorável para que os aconselhados sintam-se a vontade para discutir a respeito da aprendizagem da LE. Mozzon-McPherson e Vismans (2001) descrevem o CL como um personagem com importante atuação na educação em línguas estrangeiras, sobretudo com aprendentes adultos.

Conforme Riley (1997), o conselheiro é a pessoa que ajuda o aprendente a tomar as suas próprias decisões, tornando-o consciente de suas representações, crenças e atitudes. O conselheiro ajuda também o aprendente a identificar o seu estilo de aprendizagem e as suas preferências. Ele o auxilia a explicitar suas necessidades e objetivos de aprendizagem de línguas. O conselheiro ajuda ainda o aprendente a escolher atividades, técnicas e materiais apropriados e a elaborar um programa de aprendizagem além de ensiná-lo a monitorar e avaliar o seu progresso. Assim, podemos dizer que o CL assume o papel de uma pessoa à disposição do aprendente para ouvi-lo e ajudá-lo a encontrar melhores maneiras de aprender. Ademais, o CL 
pode prover o apoio técnico necessário, indicando caminhos para que o aprendente encontre referências importantes para subsidiar sua aprendizagem. É ainda função do CL criar momentos de reflexão juntamente com o aprendente e dar-lhe o apoio afetivo necessário para que ele passe a valorizar seus momentos de sucesso.

Segundo Mozzon-McPherson (2007, p.76), as funções dos conselheiros linguageiros são:

oferecer orientação adequada e clara e apoio para que os alunos trabalhem autonomamente; ajudar a instituição a prover oportunidades de aprendizagem de línguas apropriadas; monitorar os padrões de aprendizagem dos usuários do serviço e prover retorno relevante e eficaz; monitorar a disponibilidade de recursos disponíveis em relação às necessidades dos usuários; facilitar a habilidade dos aprendentes de se tornarem mais proficientes por meio de um melhor entendimento do seu próprio processo de aprendizagem; ouvir as necessidades dos aprendentes e elicitar conversas sobre a língua e sobre a aprendizagem.

O conselheiro linguageiro situa-se em uma área entre o professor e o monitor de centros de auto-acesso nas instituições que os têm. Ele é mais do que um professor porque atende um aluno ou um pequeno grupo de alunos de cada vez. Ele também é mais do que um monitor, porque este pode restringir-se a ajudar os alunos a encontrar materiais ou a utilizar equipamentos. $\mathrm{O}$ conselheiro linguageiro precisa de características de ambos, mas é mais do que a soma dos dois juntos. Ele também é capaz de gerar empatia com os aprendentes e precisa dominar conhecimentos sobre estilos e estratégias de aprendizagem.

Um enquadre que acolha os papeis de conselheiro e aconselhado dentro de uma atmosfera de confiança prevê que o primeiro instigue o segundo a traçar, por meio da auto-reflexão, um planejamento de ações para por em prática. Vê-se aqui a pertinência do trabalho do conselheiro na motivação, sobretudo se ela for encarada como um processo (DÖRNYEI 2001-2011), como veremos mais adiante.

$\mathrm{O}$ aconselhamento linguageiro é intimamente ligado à autonomia, uma vez que procura instaurar práticas que se estendem muito além das sessões de aconselhamento. Isso pode ocorrer se houver nessas sessões a busca de uma atmosfera que maximize a autonomia do aprendente e que minimize as intervenções em tom professoral que apontam soluções para os problemas do aprendente. Veremos melhor como isso se dá na próxima seção. 


\section{MELHORES PRÁTICAS DE ACONSELHAMENTO LINGUAGEIRO: UM ENFOQUE NA AUTONOMIZAÇÃO DOS ALUNOS}

Considerando a relevância da autonomização dos alunos nas práticas de aconselhamento linguageiro, nesta seção demonstraremos qual o papel do CL e do aconselhado ao longo desse processo por meio das evidências de autonomia ou de sua ausência nos sujeitos estudados.

Acreditamos que o processo de autonomização deve ser estimulado em qualquer contexto de aprendizagem, especialmente nas práticas de aconselhamento linguageiro, uma vez que implica em uma tomada de consciência do aprendente da necessidade de assumir a responsabilidade por sua própria aprendizagem. Ao contrário do que o termo pode sugerir, autonomia não é sinônimo de auto-instrução; não prescinde do papel do professor ou do $\mathrm{CL}$, pelo contrário, a intervenção desses agentes pode favorecer um comportamento autônomo nos alunos, levando-os a "aprender a aprender" (DICKINSON, 1994, p.2). Esse aspecto fica evidente na fala de uma das aconselhadas que acompanhamos quando ela diz:

\footnotetext{
Durante minha passagem pelo projeto conheci a mim mesma e pude me adaptar com ajuda da minha "conselheira". As atividades, sugestões e conselhos dados por ela me fizeram perceber que o sucesso no meu aprendizado só depende de mim mesma e que para isso a dedicação, prática, conhecimento da língua e confiança são elementos chaves para o meu sucesso (A1).'
}

Vemos na fala acima que a aconselhada está consciente da sua responsabilidade na aprendizagem, mas que essa consciência foi atingida com o auxílio de seu CL, o qual forneceu um andaime para que o processo de autonomização fosse colocado em marcha.

Vale ressaltar ainda que a autonomia não é uma constante, ela reflete um caráter multidimensional podendo assumir formas diferentes para cada aprendente e sofrer variações em diferentes épocas e contextos (BENSON, 2001). Por conseguinte, nas sessões de aconselhamento linguageiro, procuramos constantemente conscientizar o aluno a respeito da autonomia, protegendo seu gradativo desenvolvimento.

Em consonância com Benson (2001), Scharle e Szabó (2000) também defendem o caráter gradativo e contínuo do processo de autonomização. Para essas autoras, esse processo passa pelas fases de conscientização, mudança de atitude e transferência de responsabilidades. Seguindo e adaptando o que dizem as autoras,

1 A forma original foi mantida nas falas dos aconselhados. 
em nosso trabalho de aconselhamento linguageiro, na primeira fase, de conscientização ${ }^{2}$, encoraja-se o aconselhado a compreender melhor o processo de aprendizagem. $\mathrm{Na}$ segunda fase, de mudança de atitude, levamos o aconselhado a considerar o processo de aprendizagem sob uma nova perspectiva. Esse é um processo lento que requer muita prática e perseverança por parte do CL e do aconselhado, pois implica mudança de hábitos frequentemente fossilizados. Na terceira fase, de transferência de responsabilidades, o aconselhado passa a ser mais ativo, tomando a iniciativa e assumindo mais responsabilidades em seu processo de aprendizagem. Ilustraremos a seguir algumas ações desenvolvidas em cada uma dessas três fases nas sessões de aconselhamento linguageiro:

a) Ações desenvolvidas na fase de Conscientização:

- CL ouve o aconselhado para conhecer suas dificuldades e necessidades;

- Aconselhado faz os testes de estilos de aprendizagem e escreve uma narrativa de aprendizagem;

- CL ajuda o aconselhado a se conscientizar de que quanto melhor conhecer sua própria aprendizagem, mais utilizará as estratégias adequadas para melhorar a proficiência na LE.

b) Ações desenvolvidas na fase de Mudança de Atitude:

- Aconselhado estabelece metas pessoais a serem alcançadas na LE;

- CL propõe estratégias e atividades a serem utilizadas visando à aprendizagem autônoma da LE;

- Aconselhado tenta identificar as melhores estratégias para a própria aprendizagem;

- CL e aconselhado refletem continuamente sobre as dificuldades e avanços de sua aprendizagem durante as sessões de aconselhamento.

c) Ações desenvolvidas na fase de Transferência de Responsabilidades:

- Aconselhado toma a iniciativa propondo e utilizando novas estratégias para a própria aprendizagem;

- Aconselhado define novas metas a serem alcançadas e as próximas dificuldades a serem superadas;

- Aconselhado sugere atividades a serem realizadas para a superação das dificuldades recentemente definidas.

Constata-se que em todas as fases CL e aconselhado trabalham juntos para enfrentar novos desafios, alcançar objetivos comuns e esforçar-se para ir além deles. Para viabilizar o alcance desses objetivos colaborativamente traçados, buscase nas sessões de aconselhamento levar em consideração alguns elementos chave

2 Grifos nossos. 
para a autonomização. Dentre eles, destacamos a negociação, o treinamento, a transferência e a motivação.

Para Voller (1997), a negociação é a chave para a autonomização, uma vez que sem esta a autonomia no ensino de línguas pode tornar-se um fracasso. Nesse sentido, valorizamos o ato de negociar em todas as tomadas de decisão nas sessões de aconselhamento. Quando propomos estratégias de aprendizagem, por exemplo, oferecemos aos aconselhados uma gama de possibilidades para que eles mesmos possam escolher a mais apropriada para si. Da mesma forma, negociamos um plano de ação para a superação das dificuldades mencionadas pelos aconselhados e definimos em conjunto os prazos para o desenvolvimento de tarefas por eles selecionadas, estabelecendo juntos as prioridades das metas a serem alcançadas.

Além da negociação, Brookes e Grundy (apud BENSON; VOLLER, 1997) também sugerem o treinamento como a base para se alcançar a autonomia. Apesar de distintos, os termos negociação e treinamento estão interligados, pois o aprendente não se torna autônomo e nem aprende a negociar repentinamente, sendo necessário exercitar-se continuamente nessa prática. Apesar do que o significado corrente do termo sugere, o treinamento, no âmbito da autonomia, não se refere à prática de exercícios repetitivos e automatizadores para se alcançar com êxito determinado objetivo, mas sim à criação de oportunidades múltiplas de exercício do livre arbítrio para que o aluno reflita sobre o melhor caminho para alcançar os objetivos estabelecidos por ele durante as sessões de aconselhamento. Da mesma forma, o conselheiro aqui não exerce o papel de treinador que comanda os comportamentos do aconselhado; pelo contrário, procura abrir mão do seu poder para abrigar as necessidades do aluno. Quando nos referimos ao termo treinamento, portanto, referimo-nos a treinar o aconselhado para o uso de estratégias e atividades, as quais ele poderá lançar mão para aprender a língua. A esse respeito, Cohen (1998 apud BENSON, 2001, p.149) argumenta que o treinamento para o uso de estratégias adequadas para alcançar seus objetivos pode ajudar o aluno a:

- auto-diagnosticar suas potencialidades e dificuldades na aprendizagem da língua;

- tornar-se mais consciente do que o ajuda a aprender a língua de forma eficaz;

- desenvolver uma ampla gama de habilidades para resolver problemas;

- experimentar estratégias de aprendizagem conhecidas e novas;

- tomar decisões sobre como abordar uma atividade da língua; monitorar e auto-avaliar sua performance; e

- transferir estratégias bem sucedidas para novos contextos de aprendizagem ${ }^{3}$.

3 Grifo nosso. 
Little (1991, p. 4) reforça essa capacidade do aprendente de transferir o que e como aprendeu para outros contextos ao afirmar que "a capacidade de autonomia mostra-se tanto na maneira pela qual o aluno aprende como também na maneira pela qual ele transfere o que aprendeu para contextos mais amplos". Essa é uma das características chave do aprendente autônomo. Essa característica é fortemente incentivada no aconselhamento linguageiro a fim de que os aconselhados transfiram o conhecimento ou a experiência adquirida em determinada situação para alcançar novos objetivos de aprendizagem em contextos diferentes.

Outro aspecto diretamente envolvido na autonomia é a motivação, que será tratado de forma mais aprofundada na próxima seção deste texto. Acreditamos que "autonomia e motivação são uma via de mão dupla rumo ao sucesso na aprendizagem" (DANTAS, MAGNO E SILVA, 2008, p. 150), uma vez que quando os alunos tomam o controle da própria aprendizagem, eles passam a assumir gradativamente padrões motivacionais que garantem uma aprendizagem mais efetiva (BENSON, 2001).

Além de levar em consideração os quatro elementos chave discutidos acima, para que a autonomia se desenvolva, é necessário que o CL conscientize-se de seu papel nesse processo. Esse papel é primordialmente ir ao encontro das necessidades do aconselhado provendo escolhas que dizem respeito à sua aprendizagem, servindo de andaime, isto é, oferecendo-lhe uma orientação que possibilitará ao aconselhado realizar uma tarefa que não seria capaz de realizar sozinho (MAYBIN, MERCER; STIERER, 1992 apud MERCER, 1994). Nota-se que não é qualquer tipo de ajuda ou orientação dada aos aconselhados que pode ser considerada andaime. Em nossas sessões de aconselhamento, enfatizamos orientações que, aos poucos, capacitam o aconselhado a trabalhar por conta própria. Quando essa orientação parte dos próprios colegas, por meio do trabalho colaborativo, pode ainda ocorrer um fenômeno denominado "andaime coletivo", construído mutuamente quando os alunos compartilham seu entendimento acerca do assunto estudado ou do problema a ser resolvido (DONATO, 1994), como foi possível observar nas sessões de aconselhamento em duplas. Além disso, nas sessões conjuntas de aconselhamento linguageiro pode ocorrer o fenômeno chamado autonomia distribuída (PAIVA, 2006), no qual os aconselhados compartilham sua aprendizagem e tomam emprestado os resultados obtidos pelos colegas em um trabalho de colaboração e parceria. Observa-se que os papeis do CL e do próprio aconselhado estão em consonância com o processo de autonomização, visto que o apoio dado e recebido no aconselhamento pode levar a um comportamento cada vez mais autônomo dos aconselhados. 
Dentre os principais resultados observados no primeiro ano do projeto de aconselhamento linguageiro, destacam-se os diferentes níveis de autonomia entre os alunos atendidos. Alguns aconselhados mantém-se na fase de mudança de atitudes, resistindo a passar para a fase de transferência de responsabilidades, enquanto outros aconselhados ainda não compreendem que o esforço e a tomada de iniciativa são para eles mesmos e não para «mostrar serviço» ao seu professor ou a seu conselheiro. Acreditamos que a prática do aconselhamento tem tido resultados positivos, pois dentre os 21 alunos atendidos pelos diferentes conselheiros, apenas um recusouse a continuar com os encontros e apresentou fortes evidências de resistência à autonomia. Essa resistência configura-se em não aceitar a participação e negociação inerentes ao trabalho visando a autonomização e tem sido identificada em diferentes contextos (BROWN; SMITH iSHIODA, 2007). No sentido contrário, um outro dado relevante ocorreu quando uma das aconselhadas coordenou a montagem de um grupo de estudos com seus colegas, evidenciando altos níveis de motivação e autonomia.

Veremos na próxima seção como se dá o trabalho com a motivação no âmbito do aconselhamento linguageiro.

\section{A MOTIVAÇÃO NO ACONSELHAMENTO LINGUAGEIRO}

Nesta seção tentamos responder o porquê de a motivação ser o foco das atenções dos conselheiros linguageiros. Em seguida, descrevemos como nos preparamos para lidar com questões motivacionais detectadas nos encontros de aconselhamento. Logo depois, explicitamos alguns dos aspectos motivacionais que constatamos e apresentamos as atitudes que tomamos para favorecer a motivação dos aprendentes. Por fim, tratamos da repercussão dessas ações.

Já há algum tempo tenta-se compreender modernamente a motivação. Com diferentes abordagens estudiosos tais como Freud (1932/1966), Maslow (1970), Skinner (1953/1974) e Deci e Ryan (1985) dedicaram atenção ao assunto. No âmbito da aprendizagem de línguas estrangeiras Ushioda (1996), Gardner (2001), Brown (2007) e Dörnyei $(2000 / 2011$; 2005), entre outros, pesquisam o tema e contribuem para o entendimento desse construto. Em um plano geral, todos parecem defender que nada acontece sem motivação; que pessoas motivadas têm maiores probabilidades de serem bem sucedidas e que lidar com motivação envolve o estabelecimento de objetivos e o emprego de esforço para alcançá-los. 
Estas são as primeiras razões para trazer a motivação para o foco das atenções no aconselhamento linguageiro.

Nas pesquisas voltadas para o ensino e a aprendizagem de LE, somam-se a estas algumas outras razões para valorizar a abordagem do aspecto motivacional quando se observa que também é preciso considerar a instabilidade da motivação, as suas fases distintas e o planejamento de ações que visem gerá-la e mantê-la ativada. Entende-se, portanto, a motivação como um processo dinâmico e flutuante que acompanha a trajetória de estudos do aprendente e que influencia a tomada de suas decisões e a execução das mesmas. Assim, conselheiros linguageiros devem se preparar para saber lidar com o processo motivacional dos seus aconselhados e ajudá-los a gerenciá-lo de maneira mais eficaz.

Para isso, faz-se salutar no grupo de pesquisa a leitura e a discussão de trabalhos científicos voltados para esse fim. Dos textos lidos e discutidos pelo nosso grupo, destacamos Learners' autonomy (USHIODA, 1996) e Motivação em ação: buscando uma conceituação processual da motivação de alunos (DÖRNYEI, 2000/2011).

O primeiro propõe uma nova agenda para o professor de LE na qual se investe no processo de automotivação do aluno concomitantemente ao processo de autonomização ${ }^{4}$, enfatizando a interdependência entre autonomia e motivação. Nesta agenda de trabalho, são tarefas do professor:

- investigar o pensamento motivacional do aprendente valorizando a compreensão de suas crenças acerca de seus estudos;

- investigar as atribuições internamente construídas pelos aprendentes diante do seu sucesso ou do seu fracasso;

- ajudar o aprendente a incrementar sua motivação intrínseca.

O segundo trabalho (DÖRNYEI, 2000/2011) propõe a compreensão do processo motivacional do aprendente por meio de um modelo que inclui um eixo temporal, estruturante do processo de aprendizagem, dividido em três fases: a pré-acional, a acional e a pós-acional, nas quais um indivíduo "começa, direciona, coordena, amplifica, termina e avalia os processos cognitivos e motores por meio dos quais suas vontades e desejos iniciais são selecionados, priorizados, operacionalizados e desempenhados (com ou sem sucesso)" (p. 209). É na fase acional, ou seja, na fase da implementação de subtarefas e de condução de contínuas

4 Como visto na seção anterior, inspirados em Scharle e Szabó (2000), os conselheiros linguageiros buscam encorajar o aprendente a compreender melhor o seu processo de aprendizagem para que, mediante novas perspectivas para abordá-lo e convencido do que pode ser melhor para incrementá-lo, possa considerar a adoção de novas atitudes e de novas responsabilidades. 
e recursivas microavaliações, que o conselheiro pode exercer uma força protetora e mantenedora dos processos motivacionais em curso.

Por meio do modelo de Dörnyei (2000/2011), entendemos que a motivação do aprendente é afetada por influências motivacionais que diferem entre si e energizam de maneira distinta as ações executadas ao longo do processo de aprendizagem. Dada a instabilidade dessas influências, faz-se necessário:

- planejar e replanejar subtarefas para a execução de suas ações ao enfrentar situações imprevistas que exigem novas ponderações e possivelmente uma readequação do plano de ação;

- implementar estratégias motivacionais adequadas, visando o processo de aprendizagem mais bem sucedido e mais protegido do ponto de vista motivacional.

De acordo com estas orientações, são tarefas-chave do conselheiro linguageiro situar o aprendente no modelo processual, enfatizando o aspecto dinâmico da motivação, e também em parceria com ele:

- esclarecer os diferentes objetivos presentes em cada fase;

- negociar subtarefas para executar cada ação;

- observar as diversas influências que atuam em cada fase do processo motivacional ${ }_{i}$

- implementar estratégias motivacionais para gerar e proteger sua motivação;

- rever subtarefas, avaliar cada fase e ajustar o planejamento em parceria.

Apreendidos estes quadros teóricos nos encontros de aconselhamento linguageiro realizados, observamos a predominância de aspectos motivacionais desfavoráveis à aprendizagem dos aconselhados. Por exemplo, notamos que há aconselhados que estão mais motivados e outros menos motivados, o que é esperado, dada a individualidade e flutuação da motivação, mas nenhum deles manifestou espontaneamente que tem conhecimento de que a motivação, ou a falta dela, possa estar influenciando a tomada de decisões e as ações de cada um perante a sua aprendizagem ou que estão atentos a sua motivação, monitorando-a e protegendo-a para que aumentem as suas possibilidades de sucesso nos estudos. Além disso, nos momentos de aconselhamento foram relatadas algumas crenças prejudiciais à aprendizagem representadas pela falta de confiança no entendimento da língua estrangeira em sala de aula e receio ou vergonha de falar inglês perante os colegas.

De forma marcante, percebemos também como desfavorável à aprendizagem, a resistência de alguns aconselhados a passar da fase dos desejos para a fase da 
execução das ações necessárias para concretizar esses desejos, negligenciando inclusive a ação de tomar a iniciativa de procurar o conselheiro. Assim, houve muito mais momentos de aconselhamento provocados pelo conselheiro - um indicativo de que esses aprendentes ainda não se sentem motivados para exercer sua autonomia em relação à tomada de uma iniciativa como esta. Dessa forma, precisamos também buscar os motivos desse comportamento, tentando compreendê-lo melhor, a fim de contribuir para alterá-lo.

Por outro lado, observamos alguns aspectos motivacionais positivos expressos nesses encontros. Para alguns aconselhados, experimentar e reconhecer momentos de sucesso na sala de aula de LE foi importante para motivá-los e leválos a perseguir outros. Com a continuidade dos encontros, notamos que alguns dos aconselhados já estão estudando de maneira mais planejada e consciente para replicar os momentos de sucesso já vivenciados.

Tendo em vista estes achados e o aporte teórico apreendido, estiveram presentes entre as atitudes tomadas pelos conselheiros para lidar com a motivação dos aconselhados:

- prestar mais atenção às mensagens motivacionais que transmitimos ao aconselhado e assim criar mais empatia;

- procurar melhorar nossa capacidade de ouvi-los, de entender suas crenças e de exercitar o confronto de crenças prejudiciais à aprendizagem;

- tentar ouvir seus professores, já que eles também participam do processo motivacional do aprendente;

- tentar nos certificar em qual fase do modelo processual de motivação o aconselhado de fato se encontra;

- estar atentos para a necessidade de o aconselhado rever as subtarefas da fase acional do modelo processual;

- orientar os rumos da aprendizagem propondo mais perguntas que levem à reflexão do aprendente e menos respostas prontas para a diminuição de suas dificuldades;

- procurar conscientizar o aconselhado sobre os fatores estáveis e instáveis que influenciam sua motivação a cada momento de sua aprendizagem;

- tentar contribuir na organização dos estudos dos aconselhados;

- pedir sugestões para outros conselheiros;

- proteger nossa motivação quando compartilhamos dificuldades no grupo de pesquisa e quando recebemos sinais de que nosso trabalho tem impacto positivo na aprendizagem dos aconselhados.

Diante destas atitudes, achamos que, em alguns casos, por conta de diversas possibilidades de negociações, a aproximação maior entre conselheiro e aconselhado, o estreitamento dos laços de confiança e a mitigação de questões relacionadas 
à autoridade do conselheiro repercutiram positivamente na motivação dos aconselhados. Com isso também notamos que o trabalho de aconselhamento distanciou-se do rótulo de trabalho imposto ao aconselhado, indo em direção à busca de afinidades e necessidades reais, experimentando ações e acolhendo o aconselhado com o engajamento necessário para beneficiar sua aprendizagem. Uma evidência de que a motivação foi protegida pode ser encontrada na fala de uma aprendente quando ela relata que "as sessões vieram para mim na hora certa. Antes, quando tinha dificuldades, eu me desanimava e logo parava agora, depois que comecei com as sessões me sinto mais segura, vou tentando como eu posso, busco outras formas para estudar, aprendi a não desistir (...)" (A2). Dessa forma o CL está atuando positivamente na automotivação da aprendente.

Na nossa experiência até o momento, houve repercussão negativa em apenas um caso, já mencionado anteriormente. Corroborando a noção de interdependência entre autonomia e motivação (USHIODA, 1996), notamos que este aconselhado resistiu a exercer um comportamento autônomo e este fato possivelmente comprometeu a geração e a proteção da sua motivação. Ele recusou-se a continuar com as reuniões, pareceu indiferente à nossa proposta de trabalho e foi aos poucos se desligando do projeto, não mais mantendo contato com seu conselheiro.

Frente a essas respostas, nós conselheiros, respaldados nos estudos que passamos a conhecer, continuamos entusiasmados em aprender mais sobre como lidar com a motivação na aprendizagem de LE e, consequentemente, no aconselhamento linguageiro. Se, para tudo que fazemos precisamos de motivação e, se saber lidar com o processo motivacional pode criar oportunidades de aumento das chances do sucesso da aprendizagem de nossos aconselhados, por que deixar de fazê-lo?

A seguir, relatamos um caso de aconselhamento linguageiro que não se desenvolveu presencialmente, mas sim por meio da utilização de recursos tecnológicos.

\section{ACONSELHAMENTO LINGUAGEIRO E O EMPREGO DE INSTRUMENTOS TEC- NOLÓGICOS}

Diante das novas possibilidades advindas dos recursos tecnológicos para a aprendizagem de uma LE e das diversas pesquisas envolvendo o uso dos mesmos para o fomento da autonomia para se aprender uma LE, apresentamos a seguir alguns dados preliminares a respeito das práticas de aconselhamento linguageiro 
para produção da escrita acadêmica. Nesta seção serão demonstradas práticas de um conselheiro linguageiro executadas com o intuito de levar o aprendente com dificuldades a desenvolver textos em um gênero acadêmico a avaliar o seu próprio progresso e a agir sobre ele construindo a capacidade de assumir o controle da sua própria aprendizagem, como afirma Benson (2001) a respeito de autonomia.

As dificuldades dos alunos de graduação em desenvolver a escrita acadêmica na língua estrangeira tornam-se evidentes por ocasião da preparação do trabalho de conclusão de curso (TCC). Essa escrita é, claramente, o resultado de diversos anos de descaso com o domínio desta habilidade tanto por parte do aprendente, que a relega a uma produção que não obedece aos passos de uma escrita em processo, quanto de seus professores, que não a incentivam de uma maneira eficaz. Assim, chegam muitos aprendentes ao final de seu curso sem o hábito de autoavaliar sua produção, de reescrever seus textos e de refletir sobre eles e sobre o processo de escrevê-los.

Nosso interesse está centrado em como um conselheiro linguageiro pode atuar junto ao aconselhado para minimizar esse problema. Além disso, na impossibilidade de encontros presenciais, procuramos ver como esse trabalho ocorreu utilizando recursos tecnológicos, principalmente trocas de mensagens instantâneas pela internet e email. Os novos ambientes de aprendizagem proporcionados pelo uso de recursos como redes sociais, chats, blogs, serviços de mensagens de celular e email trazem também uma mudança na relação professor ou conselheiro e aprendente ou aconselhado. A informalidade na escrita das mensagens contrasta com a seriedade da reflexão provocada por essas trocas.

Nos cinco excertos abaixo, procuramos exemplificar como se deu essa troca. Cada trecho ilustra um tipo de posicionamento do conselheiro frente a seu aconselhado, quando aquele assume papeis tão diversos como a disponibilidade para ajudar, o apoio técnico, a reflexão assistida e o apoio afetivo.

Vemos, no primeiro excerto abaixo, como se dá a aproximação do conselheiro ao aconselhado (A3). Uma vez que essa dupla não tinha disponibilidade para um encontro presencial, julgamos importante que o conselheiro (CL) explicite o desejo de que mantenham um contato constante.

CL: como estão as suas produções E?

A3: tão indo to fazendo aki o meu capitulo 3

CL: blz! É muito importante mantermos o contato constante neste momento, a menos que vc ache que a minha ajuda não seja mais necessária e que vc já consegue resolver seus problemas de escrita sozinho

$\mathrm{A} 3 \mathrm{t} \mathrm{tdb}$... eu preciso de um ajuda ainda ${ }^{5}$

5 A forma original foi mantida nesses excertos. 
Chamamos a atenção para a não imposição do contato, ao qual o aconselhado (A3) respondeu que precisa de ajuda no momento. Desta forma, estabeleceu-se a conexão entre os dois agentes em prol do sucesso do aprendente.

No excerto abaixo, iniciado pelo aconselhado, percebemos a intervenção do CL no sentido de prover recursos técnicos para que A3 use uma variedade maior de elementos em sua escrita.

A3: ei to eenviando ta tudo feito ja ou quase

CL: blz!

A3: só que eu preciso acertar algumas coisas e fazer outras anda to te enviando oq eu ja $\mathrm{fz}$

CL: e como está sua ansiedade pra escrever?

A3: Boa ja fiz tudo so to ajeitando agora so aparar as arestas

CL: isso significa que a parte mais dificil vc já passou.

A3: so em uma analise que eu to me batendo a analise 2

CL: dificil por que? qual o problema que vc está encontrando pra escrever? essa parte

A3: pq a auala que eu analiso usa um conto e um author $\mathrm{xxxx}$ ai ta me dando trabalho de fazer a analise na escrita eu to tendo problema com os conectivos desta forma por isso dessa maneira eles se esgoratam ai eu fico num mato sem cachorro pra exemplificar e completar uma ideia

CL: com relação a essa expressões ai, eu tenho um material que pode te ajudar. vou te enviar. tem vário termos que podem ser úteis, vc vê e quem sabe exista um que vc ainda não usou?

A3: manda manda manda

CL: blz! bom infelizmente eu preciso ir! Se eu pudesse trabalharia com vc a tarde toda mas eu tenho aula. agora! querido, td de bom abraços inspiradores

Notemos no excerto acima a forma como CL incita A3 a identificar o problema ("difícil por que?"). A3, então, chega à conclusão que não possui um repertório satisfatório de conectivos e que sua escrita perde em qualidade pelo emprego repetitivo que faz de alguns desses elementos. Diante da oferta de ajuda do $C L$, ele responde entusiasticamente "manda, manda". Ressaltamos ainda que essa atitude é totalmente diferente do que simplesmente sugerir uma determinada alternativa para A3. O CL oferece a fonte para que A3 ajude a si próprio. Para A3, saber que ele pode ter alguém que disponibiliza tempo e recursos para auxiliá-lo pode atuar de forma motivadora. Conforme o tipo de diálogo que se estabelece entre conselheiro e aconselhado, este pode ser levado gradativamente a responsabilizarse pelo próprio andamento de suas tarefas. 
Nos dois excertos que se seguem, vemos como se dá o processo de reflexão assistida que foi conduzido habilmente pelo CL junto a A3.

\begin{abstract}
A3: pw num aguento mais pegar no meu tcc to stressado
CL: eu sei. Isso é assim mesmo tem horas que dá vontade de largar tudo, brigar com td mundo, mas faz parte acredite, a recompensa virá e pelo que eu vejo, c vai ser muito boa.
\end{abstract}

A3: um paragrafo sem sentido resulta na passada do horario do almoço

CL: vc já releu o paragrafo e já percebeu que ele não tem sentido

A3: sim ... aki no fim ta com uma quebra de ideia

CL: e o que vc pode fazer pra que a idéia não fique quebrada? $\mathrm{O}$ que faltou acrescentar ai?

A3: falar um pouco sobre ... deixa eu rever ... acho q falar sobre como o new criticism é usado e como ele melhora a escrita... ou como o uso do new criticism melhora as habilidades de aluno.

CL: agora é só fazer o ajuste! ei vo sair depois agent se fala

$\mathrm{A} 3$ : vo fazer isso logo $\mathrm{XD}$

Vemos que além do apoio afetivo proporcionado pelo CL ("isso é assim mesmo... a recompensa virá"), acalmando A3 e fazendo com que ele vislumbre o futuro, o CL traz $\mathrm{A} 3$ à razão fazendo com que ele perceba exatamente o que está confuso em seu texto. No final do excerto, A3, que estava cansado e desanimado, reage dizendo que irá fazer o ajuste naquele momento.

Esse entusiasmo, no entanto, não durou muito tempo, pois logo depois A3 entra novamente no chat e o seguinte diálogo acontece:

A3: acho q num vo aproveitar quase nada daquilo do qe eu fiz tava lendo aki e num bate com a ideia acima

CL: como assim?

A3: fica muito vago, tb perceb ue o paragrafo não se condiz com a ideia do texto acima e deixa vago a exposição do conteúdo anterior

CL: que bom que foi vc quem viu isso é sinal de vc começa e percebr os proprios erros e se auto-avaliar I'm so proud of you

Nesse pequeno trecho, vemos que o CL está sempre levando A3 a explicar o porquê de suas conclusões. No caso acima, assim que A3 enxerga que o parágrafo que havia escrito não se coadunava com o que vinha dizendo, o CL afirma estar orgulhoso dele por ele ter descoberto os problemas de sua escrita sozinho. Por meio deste comentário, CL contribuiu para a elevação da auto-estima de A3. 
Continuando a discussão a respeito das questões afetivas que inevitavelmente envolvem conselheiro e aconselhado, podemos ver como isso pode ocorrer observando o trecho abaixo.

A3: como a ... diz ta agoniado

CL: isso ta agoniado**

A3: é era sobre isso que eu queria conversar amanhã

CL: hey E! are you ok?

A3: no... i'm trying to finesh, my tcc and i can't write anymore.

CL: why?

A3: my head is $f . .$. hurt and my dead line is ending

CL: ok stop it! Take a breath and try to write Tomorrow

A3: tomorrow i have to give the third part done i need to cover 3 pages this night already

CL: but you can't do this tired you won't do it right take breath go to bed when I was writing my TCC I used to get tired at night because of my job and stuff and that was terrible. I couldn't do nothing right, because I was out of my mind, and until now a days every time I try to write something tired, I have to do it again in the next day.

A3: i know i need to finesh my review now if i sleep i'll never get up during the noon CL: So ... do you think you can do this tired and asleep?

A3: Nope ... I need some rest.

CL: yeah ... I mean will you be able for to figure your mistakes out if you are not feeling well. you are not a machine you need relax your brain needs a break

A3: Yeap! I will rest a little in few minutes I'll be right here 2 minutes more.

CL: Nice ... try to have a great time here and go to bed.

A3: Thanks ... I'm leaving ... Kisses!

CL: Xo Xo see you around!

A situação limítrofe exposta por A3 parece bastante grave podendo levá-lo ao desânimo maior e consequente perda de prazos para a conclusão de seu trabalho. Diante disso, o CL procura acalmar A3 usando vários recursos: compara a situação de A3 com a sua própria situação, gerando empatia, e o aconselha a descansar um pouco. Ao comparar a situação de $\mathrm{A} 3$ com a sua própria há alguns anos, o CL habilmente leva A3 a concluir que essa é uma fase transitória que não durará para sempre e por isso não é preciso chegar ao desespero. $\mathrm{O}$ aconselhado acata então a sugestão de descansar um pouco e voltar a produzir mais tarde depois de um período de repouso.

Nos excertos acima vemos que recursos tecnológicos permitem uma aproximação maior com o aconselhado, visto que os fatos e experiências podem ser compartilhados em tempo real. $\mathrm{O}$ uso desses recursos auxilia também no trabalho 
e na escolha de qual estratégia pode ser melhor utilizada naquele momento. Os recursos tecnológicos também ajudaram a manter o aluno focado no processo e não no produto, permitindo que ele assumisse um controle maior sobre sua escrita.

$\mathrm{O}$ aconselhamento linguageiro transforma a percepção do papel do professor e do aluno e também as crenças envolvidas no processo de aprendizagem de uma língua e promove uma nova maneira de lidar com o aprendente. No caso relatado nesta seção, técnicas de aconselhamento linguageiro foram utilizadas paralelamente a estratégias de escrita com o objetivo de ajudar o aprendente a levar a termo o seu trabalho ao mesmo tempo em que ele aprendia a refletir sobre o que fazer a respeito de sua escrita.

\section{CONSIDERAÇÕES FINAIS}

Neste texto expusemos as bases teóricas para o trabalho do conselheiro linguageiro e ilustramos a sua atuação no processo de aprendizagem de estudantes de Letras com habilitação em inglês. Vimos qual o papel do CL e como suas ações podem influenciar na autonomização e na motivação desses aprendentes. Alguns desses alunos já lecionam e passam a utilizar as técnicas aprendidas com seus próprios alunos, como diz uma aconselhada. Ela diz que "hoje realizo com meus alunos várias atividades que fiz no projeto. Tenho uma aprendizagem mais autônoma, pesquiso, estudo, conheço como, quando e por que posso melhorar"(A1).

Estamos cientes de que nossas próprias práticas precisam ser melhor descritas e que precisamos continuar estudando sempre para sistematizar melhor os encontros e contatos - presenciais ou virtuais - com nossos aconselhados. O tipo de linguagem utilizado, o fato de saber ouvir mais e melhor e o apoio irrestrito como provedor tanto de recursos quanto de palavras de entusiasmo podem realmente mostrar o caminho e promover mudança de atitudes em um aprendente que esteja enfrentando dificuldades na sua trajetória. É com essa esperança que continuaremos a desenvolver este trabalho. O que nos alimenta é o pensamento expresso por uma aluna que disse:

Após mais de um ano de acompanhamento, realizei sonhos dentro da minha área de atuação, faço planos futuros, tenho muito sucesso no que faço e sou mais confiante no que sou capaz de fazer. Sei que nem todas as dificuldades foram vencidas, mas aos poucos sei que posso enfrentá-las (A1). 


\section{REFERÊNCIAS BIBLIOGRÁFICAS}

BENSON, P. (2001). Teaching and Researching Autonomy in Language Learning. Harlow, England: Pearson.

BROWN, J.D. (2007). Teaching by principles: an interactive approach to language pedagogy. Englewoods Cliffs: Prentice Hall Regents.

BROWN, P.; SMITH, R.; USHIODA, E. (2007). Responding to Resistance. In: Barfield, A.; Brown, S.H. (Ed.). Reconstructing Autonomy in Language Education. Inquiry and Innovation. New York: Palgrave, pp. 71-83.

DANTAS, L.; MAGNO E SILVA, W. (2008). Motivação e autonomia para a formação de um novo aprendente e de um novo professor. In: Assis, R. (Org.). Estudo da língua portuguesa e de todas as línguas que fazem a nossa. Belém: Editora Unama, pp. 139-151.

DECI, E.; RYAN, R. (1985). Intrinsic motivation and self-deternimation in buman bebavior. New York: Plenum.

DICKINSON, L. (1994). Learner autonomy: what, why and how? In: Leffa, V. (Ed.). Autonomy in Language Learning. Porto Alegre: Editora da Universidade, pp. 2- 12.

DONATO, R. (1994). Collective Scaffolding in Second Language Learning. In: Lantolf, J.P.; Appel, G. (Ed.). Vygotskian Approaches to Second Language Research. London: Ablex, pp. 33-56.

DÖRNYEI, Z. (2000/2011). Motivação em ação: buscando uma conceituação processual da motivação de alunos, trad. Walkyria Magno e Silva e André Diniz. In: Barcelos, A.M.F. (Org.). Linguística Aplicada: Reflexões sobre ensino e aprendizagem de língua materna e língua estrangeira. Campinas: Pontes, pp. 199-236.

. (2005). The Psychology of the Language Learner. Individual Differences in Second Language Acquisition. London: Lawrence Erlbaum.

FREUD, S. (1932/1966). The complete introductory lectures on psychoanalysis. Norton: New York.

GARDNER, R. (2001). Integrative motivation and second language acquisition In: Dörnyei, $Z_{i}$ Schmidt, R. (Ed.). Motivation and second Language Acquisition. Honolulu: University of Hawaii Press, pp. 1-20.

LITTLE, D. (1991). Autonomy. Definitions, Issues and Problems. Dublin: Authentik.

MASLOW, A. (1970). Motivation and personality. New York: Harper \& Row.

MERCER, N. (1994). Neo-Vygotskian Theory and Classroom Education. In: Stierer, B; Maybin, J. (Ed.). Language, Literacy and Learning in Educational Practice. Avon, England: Multilingual Matters, pp. 92-110.

MOZZON-McPHERSON, M. (2007). Supporting Independent Learning Environments: An analysis of structures and roles of language learning advisers. In: Rubin, J. (Ed.). Counselling in Language Learning Settings. London: Longman, Special Issue of System. Vol. 35, no. 1, pp. 66-92.

MOZZON-McPHERSON M.; VISMANS R. (2001). Beyond Language Teaching Towards Language Advising. London: CILT.

PAIVA, V. L. M.O. (2006). Autonomia e complexidade. In: Linguagem \& Ensino, Pelotas, v.9, n.1, pp. $77-127$. 
RILEY, P. (1997). The guru and the conjurer: aspects of counseling for self-access. In: Benson, P.; Voller, P. (Ed.) Autonomy \& Independence in Language Learning. London: Longman, pp.114-131.

SCHARLE, Á.; SZABÓ, A. (2000). Learner Autonomy: a guide to developing learner responsibility. Cambridge: Cambridge University Press.

SKINNER, B. (1953/1974). Ciência e comportamento bumano. São Paulo: Edart.

USHIODA, E. (1996). Learner autonomy: the role of motivation. Dublin: Authentik.

VOLLER, P. (1997). Does the teacher have a role in autonomous language learning? In: Benson, P.; Voller, P. (Ed.) Autonomy \& Independence in Language Learning. London: Longman, pp. 98- 113.

Recebido: $25 / 10 / 2012$

Aceito: 21/04/2013 